\title{
Environmentally Benign and Scalable Preparation of Diethyl Furoxan-3,4-dicarboxylate Using Silver Carbonate as Nitrile Oxide Generator
}

Mao-Xi Zhang, ${ }^{*}$ Alan J. DeHope, and Philip. F. Pagoria

Lawrence Livermore National Laboratory, L-282, 7000 East Ave, Livermore, CA 94550, USA

\section{SUPPORTING INFROMATION}

1. The calibration curves

The calibration curve of the NMR integration to the concentration of furoxan $\mathbf{1}$ and $\mathbf{2}$ in the mixture was measured in $\mathrm{CD}_{3} \mathrm{CN}$ on a $125 \mathrm{MHz}{ }^{13} \mathrm{C}$ NMR spectrometer. The results are summarized in the table below.

Table S1 NMR calibration curve made from known concentration of furoxan $\mathbf{1}$ and $\mathbf{2}$ in $\mathrm{CD}_{3} \mathrm{CN}$

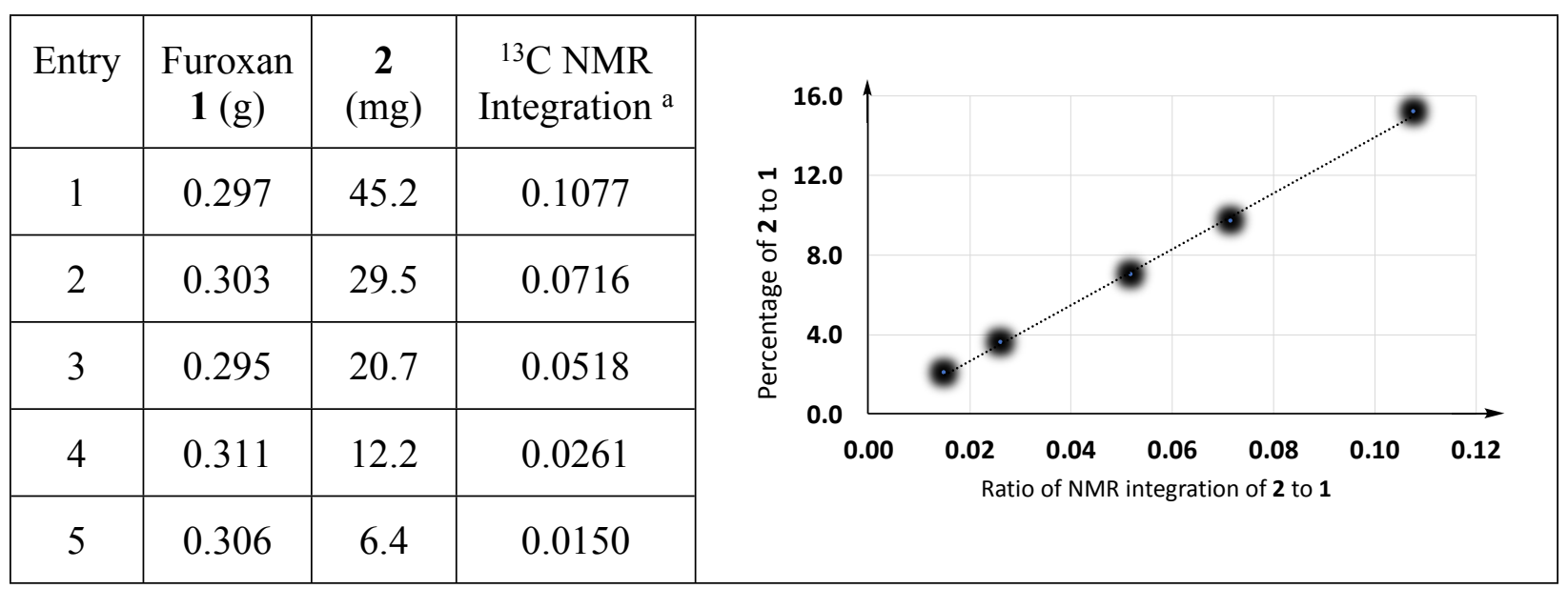

a. The ratio of ${ }^{13} \mathrm{C}$ NMR integration of methylene group of $\mathbf{2}$ and $\mathbf{1}$

The chart in the Table shows that the percentage of $\mathbf{2}$ to $\mathbf{1}$ is linearly related to the ratio of the corresponding NMR integrations. The calibration curve was served as the reference in the reaction process. 
2. IR spectrum of recycled $\mathrm{AgCl}$ measured as solid form at room temperature

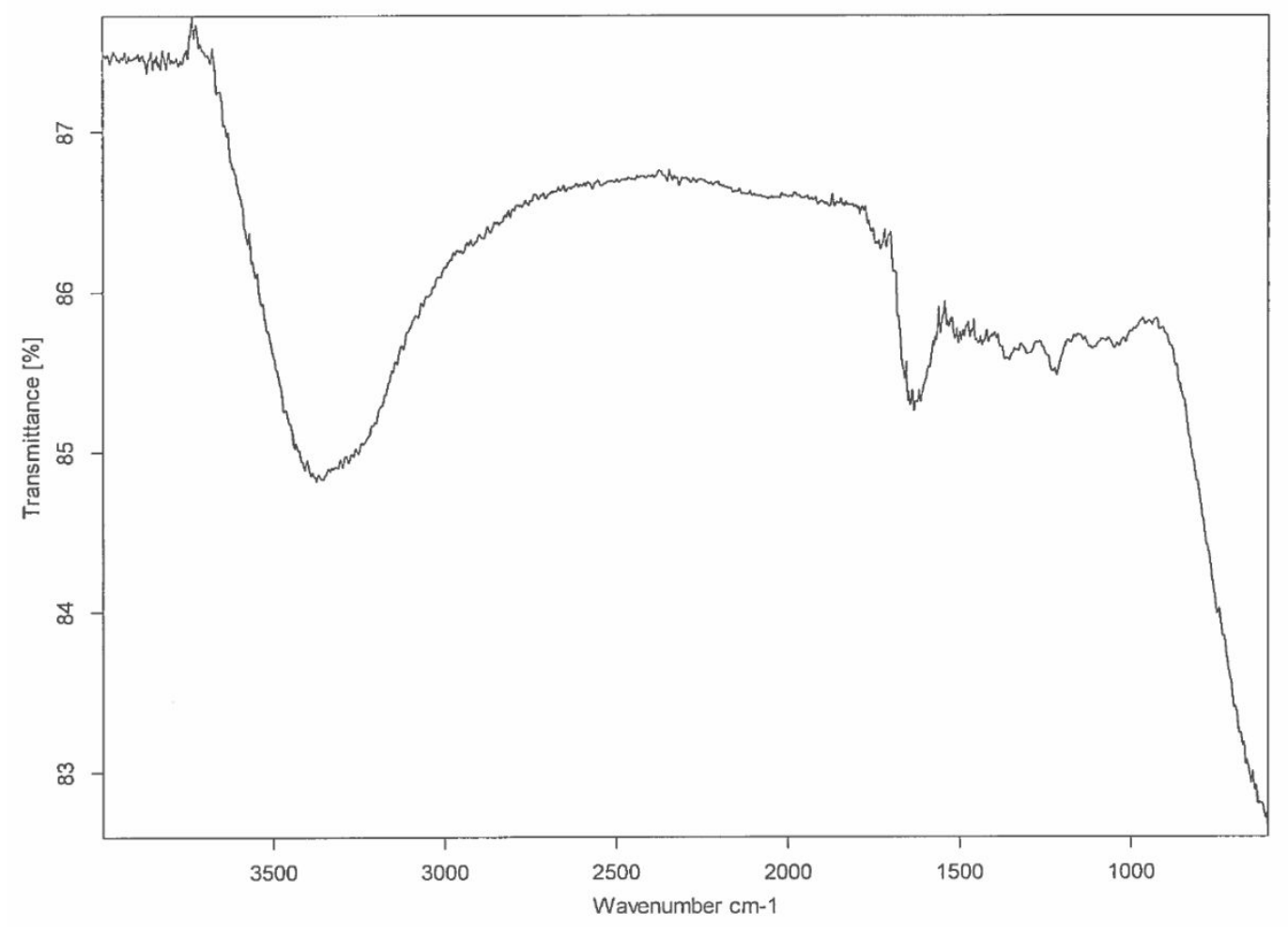

3. DSC of Furoxan $\mathbf{1}$ at $10{ }^{\circ} \mathrm{C} /$ minute

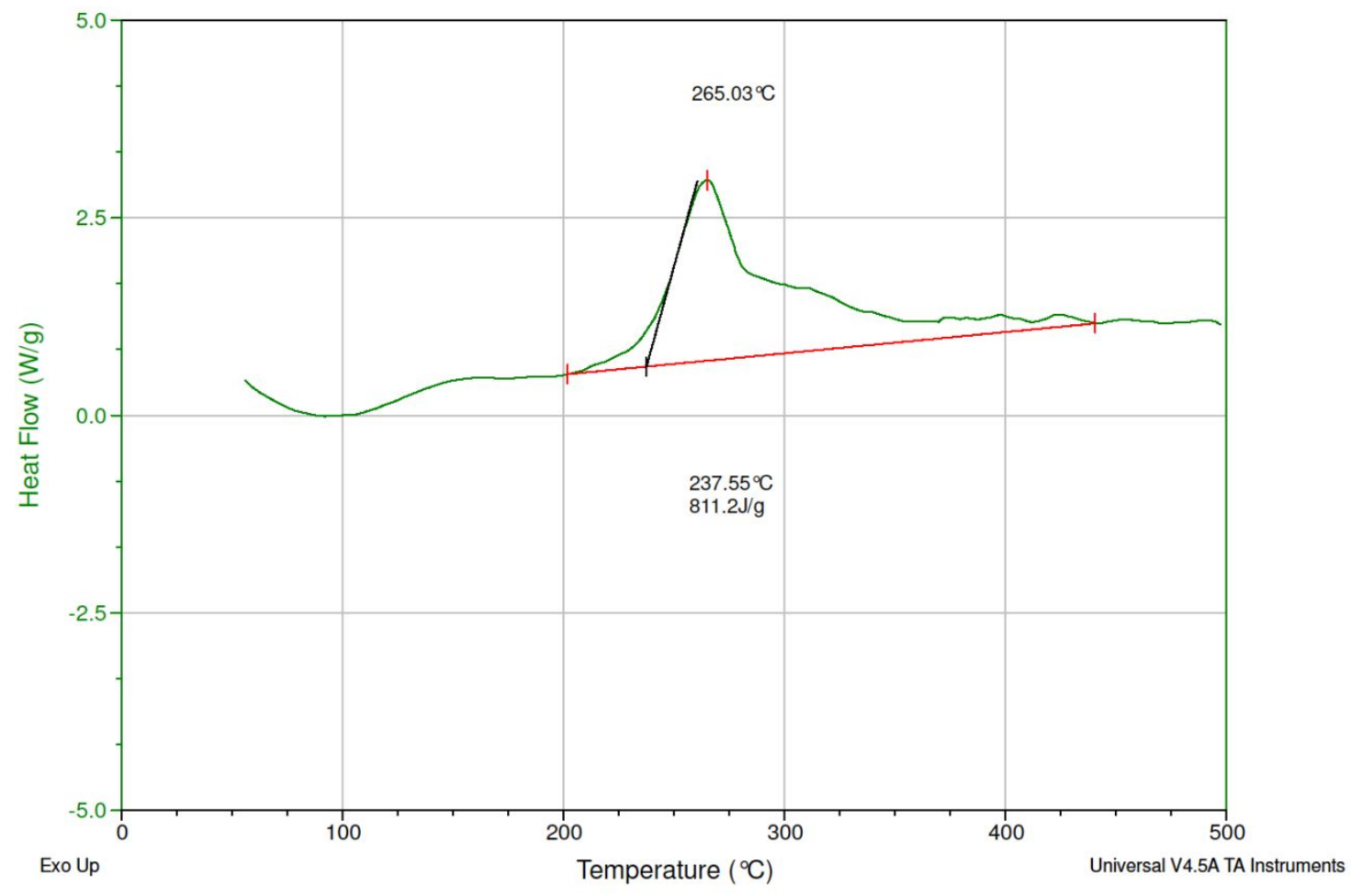

